\title{
Wild rabbit restocking for predator conservation in Spain
}

\author{
Sacramento Moreno ${ }^{a, *}$, Rafael Villafuerte ${ }^{b}$, Sonia Cabezas ${ }^{a}$, Ludgarda Lombardi ${ }^{a}$ \\ ${ }^{a}$ Estación Biológica de Dorrana, CSIC, Avda. Ma Luisa s/n, 41012 Sevilla, Spain \\ ${ }^{b}$ Instituto de Investigación en Recursos Cinegéticos (CSIC-UCLM-JCCLM), Ronda de Toledo s/n, 13005 Ciudad Real, Spain
}

\begin{abstract}
The decline of rabbit (Oryctolagus cuniculus) populations in Mediterranean Spain has been shown to be one of the main threats to rabbit-specialist predators such as the Iberian lynx (Lynx pardina) and the Spanish imperial eagle (Aquila adalberti), two species which are in serious danger of extinction. Consequently, corrective measures such as increasing rabbit populations by restocking have been carried out to help the recovery of predator populations. In order to determine the general applicability of rabbit restocking for predator conservation, we performed three experimental restockings and evaluated their success in relation to season, habitat quality and the number of animals introduced. Rabbits were released either in large or small numbers in all four seasons of the year, and in habitat types defined as 'poor' or 'rich' according to the food availability for rabbits. For each restocking we evaluated rabbit survival, degree of residency and expected population increase. As a rule, the highest restocking success occurred whenever smaller number of rabbits were released in the richest quality habitat. Restocking during the breeding season was less successful than in other seasons. Problems concerning intraspecific competition, reproductive failure and diseases are discussed.
\end{abstract}

Keywords: Threatened predator; Rabbits restockings; Oryctolagus cuniculus; Wildlife conservation

\section{Introduction}

The Spanish imperial eagle (Aquila adalberti) and Iberian lynx (Lynx pardina), both endemic to the Iberian peninsula, are among the most threatened predators in the world (Nowell and Jackson, 1996; Delibes et al., 2000; Ferrer, 2001). Both species evolved in the Iberian peninsula about one million years ago (during the first glaciation of the Quaternary period, Ferrer and Negro, personal communication) and are currently only found in Mediterranean forest and scrublands in southwest Spain. These top predators are extremely well-adapted to preying on wild rabbits (Oryctolagus cuniculus) $(88 \%$ of diet, Delibes et al., 2000; Ferrer, 2001) and the most important factor affecting the risk of extinction of both species is the fall in wild rabbit numbers (Palomares et al., 2001; Ferrer, 2001). The wild rabbit is native to the Iberian Peninsula and constitutes a key species in Iberian Mediterranean ecosystems, being the main prey

\footnotetext{
* Corresponding author. Tel.: +34-954-232340; fax: +34-954-621125.

E-mail address: smoreno@ebd.csic.es (S. Moreno).
}

item for more than 20 avian and mammalian predators (Delibes and Hiraldo, 1981). Rabbits in Spain are also an important game species (Rogers et al., 1994). Recently, two diseases - myxomatosis and viral haemorrhagic disease - and the loss of suitable habitat have led to an important decline in rabbit numbers (Moreno and Villafuerte, 1995) and have affected the abundance of specialist predators. As a result, and because rabbit scarcity in Spain constitutes a serious problem for wildlife conservation, the European Union and Spanish Government have drawn up recovery plans for these highly threatened predators (ICONA-CSIC, 1988; LIFE-CE, 1992), which involve the spending of more than 15 Euros million and include among their main goals an increase in habitat carrying capacity by boosting the number of rabbits.

In some protected areas habitat improvement through the increase of food availability has been shown to be a good management technique for increasing rabbit numbers (Moreno and Villafuerte, 1995) in the long-term. As the situation of the Iberian lynx and Spanish imperial eagle is so critical, other management techniques aimed 
at increasing rabbit abundance in the short-term have been called for by conservationists. Therefore, rabbit restocking is now being planned in areas such as the Donana National Park (SW Iberian peninsula), one of the most important reserves for this species of eagle and the Iberian lynx, where these threatened predators live. Because restocking or translocations have never been performed in any protected area in Spain, an experimental rabbit restocking project was carried out in Dorrana in order to evaluate the potential success of such a management technique. Little information exists on efforts to increase rabbit abundance (Moreno and Villafuerte, 1995; Calvete et al., 1997), since most efforts are usually performed in areas where rabbits are an introduced pest, and where conservation and research efforts aim to reduce rabbit numbers (Fenner and Fantini, 1999; Angulo and Cooke, 2002).

In Spain, rabbit restocking is frequently carried out for hunting purposes, with thousands of individuals being introduced every year. However, these actions often end in failure and in negative consequences for nature conservation (Calvete et al., 1997); the mechanism underlying these processes remains largely unknown.

This paper reports the results of an experiment in rabbit restocking. The specific objectives were to evaluate if success depends on: (1) time of the year at which restocking takes place (i.e. if rabbit reproductive status and abundance in the release area are factors related to success); (2) habitat quality, measured as scrub cover for shelter and food availability; and (3) the number of rabbits released.

The number of introduced rabbits remaining in the release area is one of the most important criteria in evaluating restocking success (Nielsen, 1988; Robinette et al., 1995). It is therefore necessary at least to compare survival, dispersal movements and the increase in abundance in the release area with other similar control areas where only resident rabbits live and no restocking has been performed. Since restocking may also involve an impact on resident rabbits (Karesh, 1993; GalindoLeal and Weber, 1994), whenever possible we monitored both introduced and resident rabbits.

The overall goal of this study is to evaluate the efficiency of rabbit restockings in protected areas in the Mediterranean where rabbit predators are in a critical situation.

\section{Methods}

\subsection{Study area}

The Dorrana National Park $\left(37^{\circ} 10^{\circ}, 6^{\circ} 23^{\circ} \mathrm{W}\right)$ occupies almost $550 \mathrm{~km}^{2}$ of the north bank of the mouth of the Guadalquivir River (Fig. 1). Its climate is Mediterranean, with hot dry summers (average August temperature $25^{\circ} \mathrm{C}$ ) and mild wet winters (average January temperature $10{ }^{\circ} \mathrm{C}$, average annual rainfall $600 \mathrm{~mm}$ ). It has three main biotopes: sand dunes, marshland and scrubland (Valverde, 1958; Castroviejo, 1993), with rabbits occurring mainly in the latter (Lombardi et al., 2003). Two main scrubland types are clearly distinguishable and named generically 'wet' and 'dry' scrubland (Fig. 1).

The Dorrana National Park is one of the most important protected areas in Europe, and one where most mammal and raptor carnivores feed on rabbits
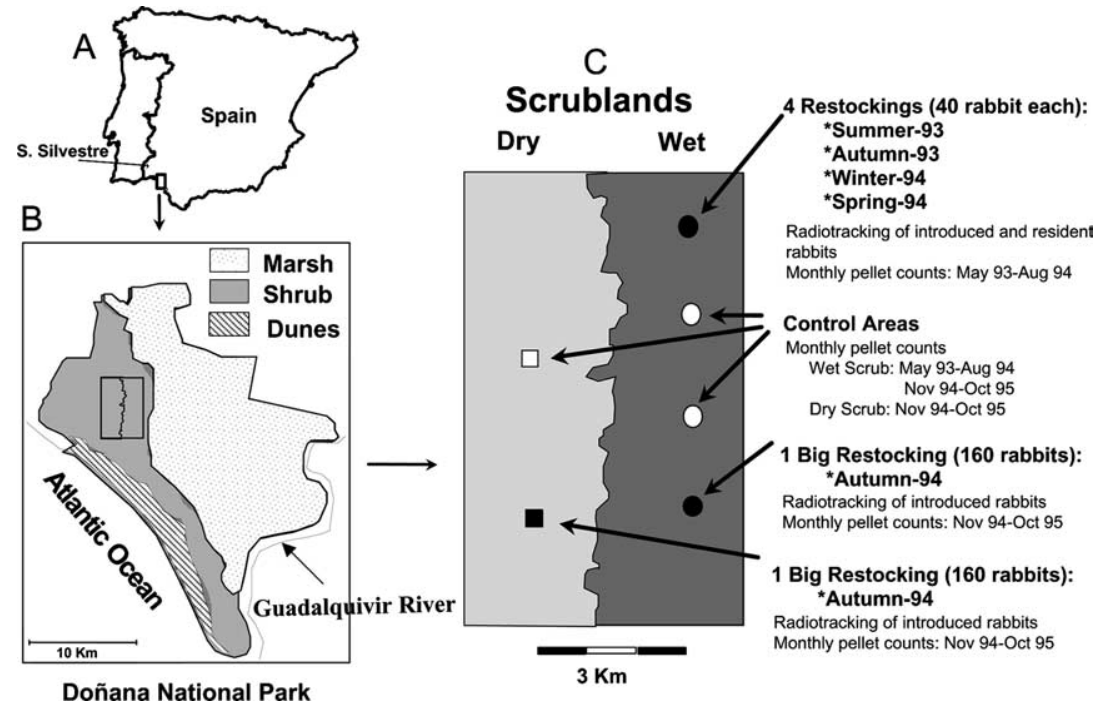

Fig. 1. (A) Location of the Donana National Park and S. Silvestre de Guzmán (source area). (B) Main biotopes in the Dorrana National Park and situation of the study area. (C) Scheme of the experimental restocking, showing scrub types, number of rabbits introduced, locations of control and release areas, and dates. 
(Villafuerte, 1994; Moreno et al., 1996). Hunting is forbidden in the National Park.

Study areas were located in both wet and dry scrubland types. Rabbits were commoner in wet scrubland (around 15-20 rabbits/ha in June-July) than in dry scrubland (2-5 rabbits/ha in June-July; Moreno and Villafuerte, 1995), although these densities are progressively decreasing. The quality and abundance of the herbaceous layer are also greater in wet scrubland (Villafuerte et al., 1997).

The wet scrubland is adjacent to a wide grassland area surrounding the marshland. It is a community of low scrub $(>1.5 \mathrm{~m})$ adapted to sandy soils where the water table is located at $=2 \mathrm{~m}$ below the surface. The most characteristic plant species are Halimium halimifolium, H. commutatum, Stauracanthus genistoides, Ulex australis and Urginea maritima (67\% scrub cover). Some dispersed patches of dense Atlantic vegetation (Erica scoparia, E. umbellata and Calluna vulgaris) are also common in this habitat. The availability of fresh herbaceous biomass in October 1994 was 13,025 kg/ha (unpublished data).

Dry scrubland has a deeper water table $(=10 \mathrm{~m})$ than wet scrubland and a sandy soil with a characteristically homogeneous flora consisting of xerophyte Mediterranean scrubland ( $55 \%$ scrub cover and $<1.5 \mathrm{~m}$ height) of H. halimifolium and Rosmarinus officinalis. Food abundance in October 1994 was $5375 \mathrm{~kg} / \mathrm{ha}$ of fresh herbaceous biomass.

\subsection{Rabbit handling}

To avoid any genetic differences between resident and introduced rabbits, we first analysed the genetic similarities between rabbits from the Dorrana National Park and from several potential donor populations in neighbouring localities, none of which were able to naturally colonize Donana (Ferrand et al., 1993; Branco, 1996). Among the five potential source populations the rabbits from San Silvestre de Guzmán, Huelva $\left(37^{\circ} 23^{\circ} \mathrm{N}, 7^{\circ} 20^{\circ}\right.$ W; Fig. 1) presented the least genetic differences (Ferrand et al., 1993; Branco, 1996) from the Dorrana population and so were chosen for the experimental restockings.

Rabbits from the donor population were captured using trap-nets. Adult rabbits (>800 g) were taken to a quarantine shed, where they were caged in pairs (male and female). The animals were ear-marked with numbered metal tags, weighed and measured. They were then vaccinated against myxomatosis, rabbit haemorrhagic disease and treated for external and internal parasites, in order to minimise disease and parasite transmission (Chivers, 1991; Woodford, 1993; Viggers et al., 1993; Meltzer, 1993) to resident rabbits.

After two weeks in quarantine, the rabbits were released into the study areas. The sex ratio was 1:1 in all released lots, as occurs in natural populations in the Dorrana (Villafuerte, 1994). Releases were carried out at midnight. In all cases, a sample (see Section 2.3) of each stock of introduced rabbits was fitted with radio transmitting collars ( $20 \mathrm{~g},<2 \%$ body weight) with activity sensors (BIOTRACK, Wareham, England).

Resident rabbits in the release areas were also caught with trap-nets, ear-tagged, weighed, measured and fitted with radio collars (but not vaccinated).

\subsection{Experiment design}

In the three restocking experiments, we considered three factors when analysing the success of each restocking event: time of the year (from here on 'season'), habitat type and number of rabbits introduced. One release and one control area ( $=15$ ha each) for each experiment were selected for our study (Fig. 1). Control areas were chosen that were similar to release areas, both in habitat characteristics and previous rabbit abundance (see Section 2.1). Rabbits were not introduced in the control areas or close by. To ensure independence between areas (i.e. no rabbit exchange), control and experimental areas were located $>2 \mathrm{~km}$ away from each other.

\subsubsection{Evaluation of success according to restocking season}

This experiment was designed to assess whether releases at certain crucial stages in the rabbits' demographic cycle would be more successful. The stages chosen were: (1) June, the post-breeding period, just when reproduction was finishing; (2) October, the nonbreeding period; (3) January, just when reproduction was starting; and (4) April, the breeding period. We selected wet scrubland for the experimental restocking. In all four seasons groups of 40 rabbits were introduced at a single site in wet scrubland. Ten ( 5 males and 5 females) out of every set of 40 introduced rabbits were fitted with radio collars. Just before release, adult resident rabbits were captured in the release area and also fitted with radio collars $(6,7,10$, and 9 rabbits in each period, respectively, making a total of 32 rabbits). To measure survival rates, mortality rates and spatial behaviour, both introduced and resident rabbits were monitored for 90 consecutive days (a complete season).

We compared seasonal variation in survival rates (resident and introduced populations), movements (resident and introduced) and rabbit abundance (release vs. control sites).

2.3.2. Evaluation of success according to habitat quality

On 14 October 1994, a total of 320 rabbits (160 in each area) were simultaneously released in the dry and 
wet areas; 12 rabbits in each area were radiotagged (6 males and 6 females). During a 90-day period, comparisons between the survival, movements and dispersal of released rabbits in wet and dry scrubland were carried out. No resident rabbits were radiotagged as part of this experiment.

Rabbit abundance was measured in the two release areas and two control areas from November 1994 to October 1995.

\subsubsection{Effects of releasing varying numbers of rabbits}

To compare the effectiveness of releasing different sized groups of rabbits, we compared the data (survival, movements, dispersal and increase in abundance) obtained from a single group of 40 rabbits with that obtained from the group of 160 rabbits. Data from the second restocking (autumn 1993) in wet scrubland, when 40 animals were released, were compared with another restocking carried out in the same scrub type (in the same season of 1994), when 160 rabbits were released in the same habitat type in a similar sized area. To verify whether it might be possible to compare results from 1993 and 1994, we carried out a correlation analysis between the seasonal abundance pattern of rabbits in the two control areas for 1993 and 1994.

\subsection{Survival and mortality rates}

All radiotagged rabbits were located daily (usually at dusk, dawn, midnight and midday) to determine their position and whether they were dead or alive. When animals were thought to be dead (e.g. lack of activity for a long period or located in an unusual place) we investigated and searched for the dead animals. The cause of death was determined by examining the carcass, by identifying bite marks on the body and radio collar, by the location of the remains and by other signs (feathers, faeces, tracks, etc.). Whenever possible, tissue or blood samples were also collected for further disease analyses.

Data analyses of survival and mortality rates were calculated by using the MICROMORT software programme (Heisey and Fuller, 1985), which provides information on survival by taking into consideration the number of days that each rabbit was alive. As this programme provides survival rates assuming a normal distribution, differential mortality rates are given with $95 \%$ confidence intervals. Such results were compared using the $\mathrm{z}$ statistic:

\section{$\mathrm{Z} 1 / 4 \mathrm{M} 1-\mathrm{M} 2=ð \mathrm{~V} 1$ p V 2 p 2ð $\operatorname{Cov}_{1 ; 2} \mathrm{pp} 2 ;$}

where $\mathrm{M} 1$ and $\mathrm{M} 2 \frac{1}{4}$ mean mortality rates compared; V 1 and V $2 \frac{1}{4}$ variances; Cov $1 / 4$ covariance.

Annual and seasonal survival rates $(1-\mathrm{M})$, as well as mortality rates caused by different factors (predators, diseases or unknown causes) were calculated.
2.5. Analysis of spatial behaviour: movements and dispersal

Several spatial variables from the radiotagged rabbits were measured to evaluate the movements of introduced rabbits, whenever possible in comparison with simultaneously monitored resident rabbits.

The maximum distance travelled (MDT) by each rabbit was calculated as the distance from the release point to the furthest recorded location. The mean distance between two consecutive fixes, hereafter the interfix distance (ID), was calculated as an index of individual rabbit mobility (Norrdahl and Korpim@ki, 1998).

We expected introduced animals to be stressed after restocking (Calvete et al., 1997; Letty et al., 2000) and so we also calculated the time rabbits spent in settling in a fixed area. We arbitrarily considered that a rabbit had settled when for three or more consecutive days the ID was less than all of its averaged values for that index. We were able, therefore, to calculate the number of days it took to settle.

We calculated two indices for dispersal. A dispersal index (DI) was estimated by averaging the distance between all the locations of each individual rabbit and all the locations of the rest of the radiotagged animals. Thus, the index we obtained was unaffected by different sized home ranges. Secondly, we calculated the mean dispersal distance from the release point (DRP) as the average distance of all locations of each rabbit from the release point. Statistical analyses of spatial behaviour were carried out using Kruskal-Wallis $(\mathrm{K}-\mathrm{W})$ and ANOVA/ANCOVA tests (Conover, 1980).

\subsection{Rabbit abundance}

Population abundance was evaluated in all the release and control areas, i.e. in similar habitat zones where no rabbits were introduced.

The evaluation of rabbit abundance was derived from pellet counts (Palomares, 2001). Pellets were collected and counted monthly in 30 randomly distributed circular sampling units $\left(1.54 \mathrm{~m}^{2}\right)$ in each release and control area.

\section{Results}

3.1. First experiment. Evaluation of success according to restocking season

\subsubsection{Survival}

Most deaths amongst the introduced rabbits occurred during the first few days after release. Survival rates were similar over three seasons (summer, autumn and winter), the exception being the low survival rate 
exhibited by resident rabbits in winter, when a significant difference was found from the survival rate of introduced rabbits $\left(\mathrm{z}^{1} \frac{1}{4} 3: 29, \mathrm{P}<0: 001\right.$; Table 1$)$. In this season disease (RHD) killed at least $30.8 \%$ of the resident rabbits (Table 1). Due to the effect of these winter deaths, the annual survival rate for resident rabbits was significantly lower than for introduced rabbits $(\mathrm{z} 1 / 4$ 1:96, $\mathrm{P}<0: 05)$.

\subsubsection{Spatial behaviour}

In every restocking period, most of the introduced rabbits survived and settled. An average of 8.3 days was needed to settle, regardless of sex or season (Table 2), although animals seemed to settle more quickly in winter and more slowly in summer (14.6, 6.9, 3.7 and 7.4 days, for summer, autumn, winter and spring respectively).

The maximum distances travelled were similar for resident and introduced rabbits, but varied according to season, being greater in autumn and winter (Fig. $2 \mathrm{a}$ and Table 2).

The IDs of introduced rabbits were significantly greater before settling than afterwards (187 vs. $116 \mathrm{~m}$; $\left.\mathrm{F}_{1 ; 62} 1 / 46: 25, \mathrm{P} 1 / 40: 014\right)$. IDs were shorter for resident rabbits. In both rabbit groups (resident and introduced), the ID increased from summer to autumn/winter, and then decreased significantly in spring (Fig. 2b).
The mean dispersal distance from the release point was similar for both resident and introduced rabbits, except in the case of winter release. During spring, introduced rabbits seemed to stay closer to release points, although these seasonal differences were not significant (Table 2 and Fig. 2c).

The DI ranged from $164.5 \mathrm{~m}$ (resident, summer) to $404.5 \mathrm{~m}$ (introduced, spring) (Fig. 2d) and was significantly affected by sex (being smaller for females), season (being smaller when restocking occurred in summer) and origin (being smaller for resident rabbits) (Table 2).

\subsubsection{Rabbit abundance}

At the start of our study, no significant differences were found between rabbit abundance in the control and in the release areas (t-test $1 / 40.940, \mathrm{P} 1 / 4$ 0:351). The seasonal pattern of rabbit abundance in the control area was similar to that previously described for the Donana (Beltrán, 1991), i.e. maximum values corresponded to spring and early summer, decreasing in autumn and winter.

Monthly average abundance values were correlated between release and control areas ( $\mathrm{r} 1 / 4$ 0:811, $\mathrm{P}<0: 001$, $n 1 / 415$ ). However, probably because of an increase caused by each restocking process, the annual pattern of abundance in the release area was more even, and only slight differences between maximum and minimum

Table 1

Number (survivor/total), survival rates (mean, maximum and minimum, 95\% confidence limits) and variance of survival rates to the third month of release for resident and introduced rabbits in the four seasonal experimental restockings

\begin{tabular}{llll}
\hline Station restocking & Number & Survival rate & Variance \\
\hline Summer & Resident (5/6) & $0.824(0.563-1.00)$ & 0.026 \\
& Introduced (7/10) & $0.769(0.535-1.00)$ & 0.020 \\
Autumn & Resident (6/7) & $0.831(0.578-1.00)$ & 0.024 \\
\multirow{2}{*}{ Winter } & Introduced (8/10) & $0.71(0.482-1.00)$ & 0.020 \\
& Resident (3/10) & $0.119(0.024-0.568)$ & 0.009 \\
Spring & Introduced (8/10) & $0.777(0.548-1.00)$ & 0.019 \\
& Resident (6/9) & $0.671(0.427-1.00)$ & 0.024 \\
\hline
\end{tabular}

Table 2

Analysis of the covariance tables of the different variables used to measure the spatial and temporal behaviour of rabbits and to test the effect of season and origin (resident and introduced rabbits)

\begin{tabular}{|c|c|c|c|c|c|c|c|c|c|c|}
\hline \multirow[t]{2}{*}{ Sources of variation } & \multicolumn{2}{|c|}{ Time to settle $\mathrm{e}^{\mathrm{a}}$} & \multicolumn{2}{|l|}{ MDT } & \multicolumn{2}{|l|}{ ID } & \multicolumn{2}{|c|}{ Dispersal from release point } & \multicolumn{2}{|l|}{ DI } \\
\hline & Df & $\mathrm{F}$ & Df & $\mathrm{F}$ & Df & $\mathrm{F}$ & Df & $\mathrm{F}$ & Df & $\mathrm{F}$ \\
\hline \multicolumn{11}{|l|}{ Covariates } \\
\hline Individual & 1,34 & 1.75 & 1,58 & 1.73 & 1,58 & 1.5 & 1,48 & 1.4 & 1,317 & 0.09 \\
\hline Sex & 1,34 & 0.90 & 1,58 & 2.81 & 1,58 & 1.9 & 1,48 & 3.4 & 1,317 & $7.68^{++}$ \\
\hline Season & 3,34 & 1.41 & 3,58 & $5.16^{++}$ & 3,58 & 1.5 & 3,48 & 2.61 & 3,317 & $5.38^{++}$ \\
\hline Origin & & & 1,58 & 1.55 & 1,58 & $3.87^{+}$ & 1,48 & 2.4 & 1,317 & $4.26^{+}$ \\
\hline Season $^{+}$Origin & & & 3,58 & 0.93 & 3,58 & 0 & 3,48 & 1.3 & 3,317 & 2.45 \\
\hline
\end{tabular}

${ }^{\mathrm{a}}$ Only introduced rabbits.

${ }^{*} \mathrm{P}<0: 05$.

${ }^{* *} \mathrm{P}<0: 01$. 

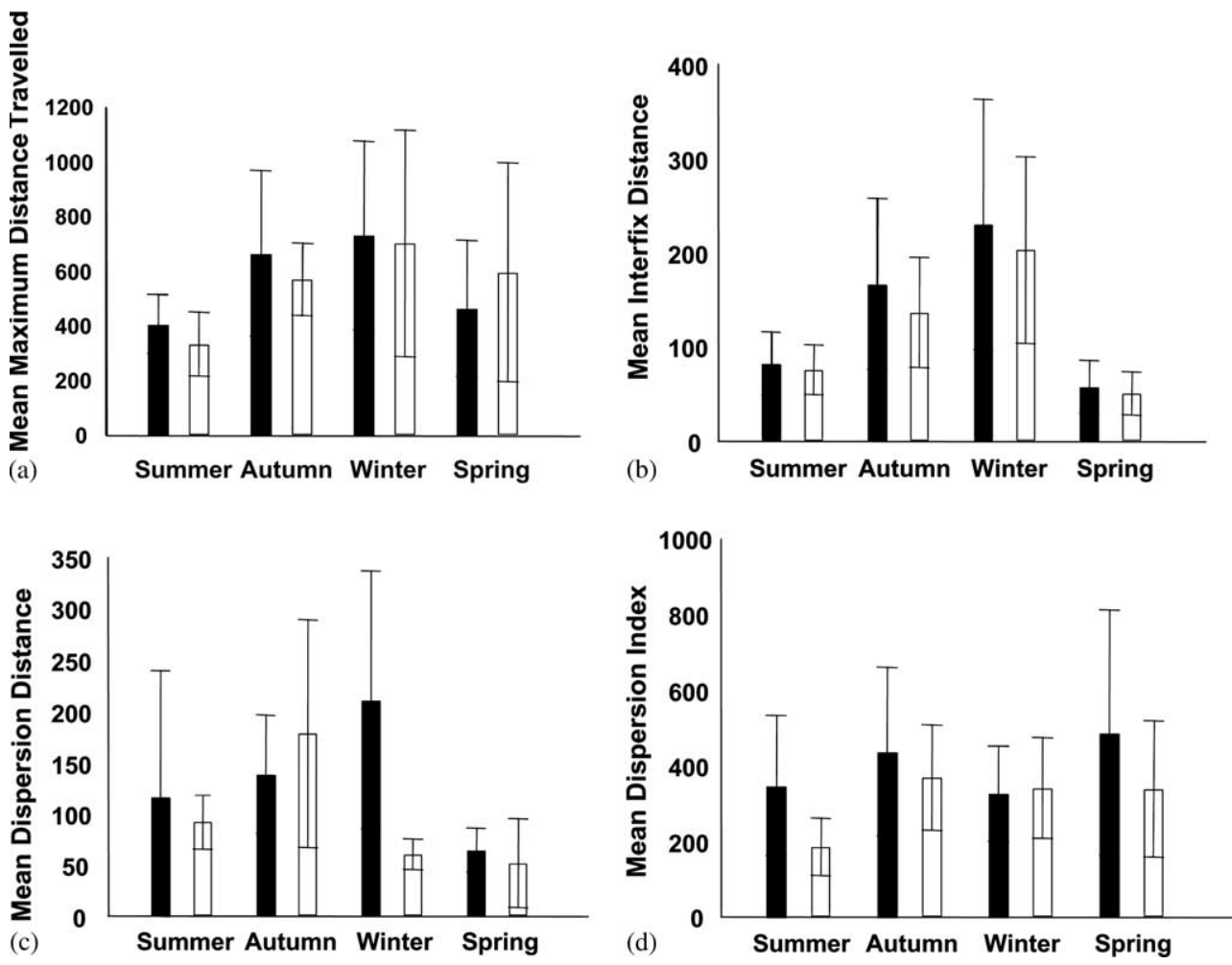

Fig. 2. Mean, maximum and minimum (95\% confidence limits) values of seasonal values of (a) maximum distances reached by animals from the release point, (b) ID (mean distance between two consecutive fixes), (c) dispersal from the release point (mean distance of all locations of each animal from the release point, and (d) DI (mean distance of all locations of each rabbit to all locations of other rabbits). Shaded bars refer to introduced rabbits, white bars to resident rabbits.

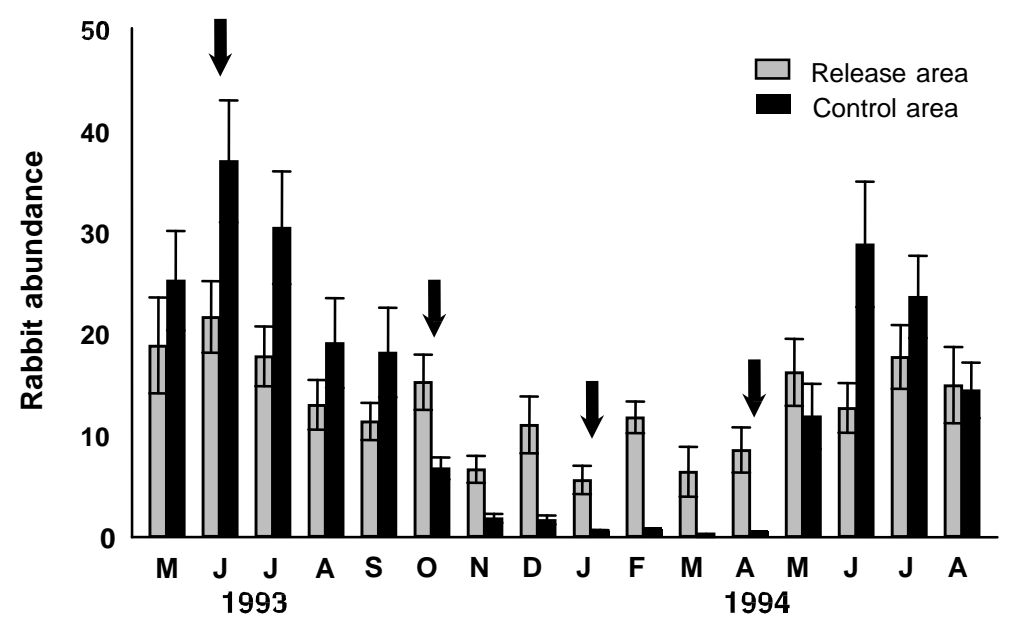

Fig. 3. Values of abundance in the release area related to abundance in the control area from June 1993 to August 1994. Arrows indicate the timing of each small restocking (n $1 / 440$ individuals).

population levels were observed (Fig. 3). The most striking result was the absence of the expected postbreeding maximum (June-July) in the release area, which however was evident in the control area. Values of abundance in the release area related to abundances in the control area are shown in Fig. 3.
No extra increase in numbers was evident during the first restocking in summer. A slightly greater rise was found in autumn, whilst there was an $18 \%$ relative increase in winter. Spring restocking caused an important relative reduction in numbers in the release area with respect to the control area, in spite of the higher number 
of rabbits inhabiting the area during the pre-breeding period (Fig. 3).

3.2. Second experiment. Evaluation of success according to habitat quality

\subsubsection{Survival}

Seven of the 12 radiotagged animals introduced in the wet scrubland survived throughout the whole monitoring period. All deaths occurred in the first week after release. However, in dry scrubland, only one of the 12 monitored animals survived the whole 90-day study period, while one rabbit was never relocated. Most rabbit deaths (n $1 / 46)$ occurred during the first week, the remaining animals died between the 12th and the 69th day after release. The estimated survival rate for introduced rabbits in wet scrubland during the three-month period was therefore significantly higher than for dry scrubland (0.43 vs. $0.026 ; \mathrm{z}^{1 / 4}$ 2:66, $\mathrm{P} 1 / 4$ 0:004).

The most important causes of mortality in wet scrubland appeared to be predation by foxes (Vulpes vulpes) (3 out of $5,37.88 \pm 28.9 \%$ at $95 \%$ confidence limits), lynxes (1 out of $5,9.5 \%$ ) and mongooses (Herpestes ichneumon) (1 out of $5,9.5 \%)$. In dry scrubland, foxes were also the main cause of mortality (74.84 $\pm 25.1 \%$ at $95 \%$ confidence limits), while predation by mongooses caused a mortality rate of $21.38 \pm 23.5 \%$. Some rabbits were also found to have been killed, but not eaten. No other causes of death were detected.

\subsubsection{Spatial behaviour}

The time needed to find a site to settle in seemed to be greater in wet scrubland than dry scrubland, although differences were not significant. The maximum distances travelled by introduced rabbits before settling in wet scrubland were significantly lower than those in dry scrubland (457.1 vs. $1026.8 \mathrm{~m} ; \mathrm{K}-\mathrm{W} 1 / 43.85 ; \mathrm{P}<0: 05$ ). There were no significant differences between IDs in dry and wet scrubland (K-W 1/4 0.80; ns).

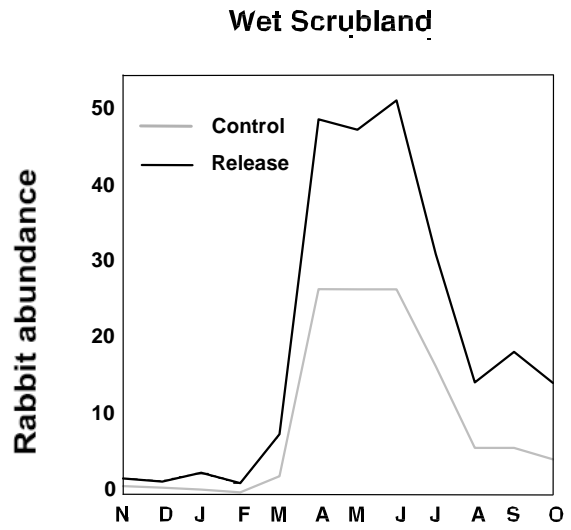

Dispersal from release points was not significantly different for introduced rabbits in wet or dry scrubland (K-W $1 / 41.1$; ns). Distances to other rabbit locations (DI) were significantly lower for introduced rabbits in the wet habitat (mean \pm SE: $508 \pm 52$ ) than for those in the dry habitat (mean \pm SE $1 / 41017 \pm 105 ; F_{1 ; 129} 1 / 4$ 17:3; $\mathrm{P}<0: 001)$.

\subsubsection{Rabbit abundance}

The results of pellet monitoring in the release and control areas of the two habitat types showed parallel annual patterns, increasing during spring and decreasing from summer to winter (Fig. 4). Initial winter abundance in control and release areas of both habitat types were similar (t-test, wet $1 / 42.13, \mathrm{P} 1 / 40: 151$; dry $1 / 41.00$, $P 1 / 40: 321)$. At the end of the study period, rabbit abundance in the release area was significantly higher than in the control area in wet scrubland (t-test $1 / 43.53$, $\mathrm{P}<0: 001)$, whereas in dry scrubland there were no differences between abundance in the release and control areas (t-test 1/4 0.105, P 1/4 0:917). The dry habitat release area recorded lower numbers compared to its respective control, as shown in Fig. 4.

3.3. Third experiment. Evaluation of success of large vs. small numbers of introduced rabbits (40 vs. 160)

We compared the initial rabbit abundance and the seasonal abundance pattern between 1993 and 1994 for the control areas in wet scrubland; no differences were found (t-test $1 / 40.481, \quad \mathrm{P} 1 / 4$ 0:636; $\mathrm{r} 1 / 4$ 0:33, $\mathrm{P}$ 1/4 0:28). Therefore, to evaluate differences in releasing small or large numbers of rabbits in autumn, we compared the success of the restocking of 40 rabbits in October 1993 with the restocking of 160 rabbits in October 1994 in wet scrubland.

\subsubsection{Rabbit survival}

Survival rates of radiotagged rabbits introduced in a smaller group were higher than for rabbits in larger

\section{Dry Scrubland}

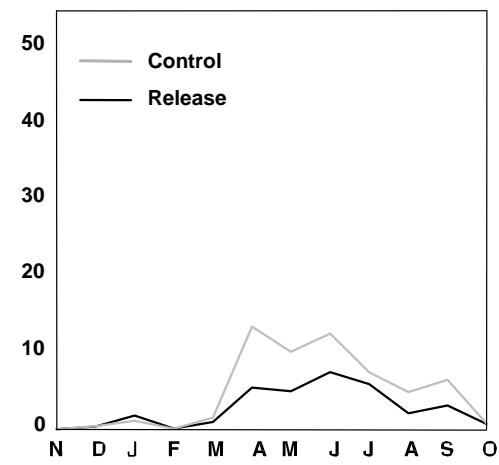

Fig. 4. Annual patterns of rabbit abundance (measured by pellet counts) in control (light line) and release (dark line) areas in both wet and dry scrubland habitats. Restocking of 160 individuals in each habitat type was performed in October 1994. 


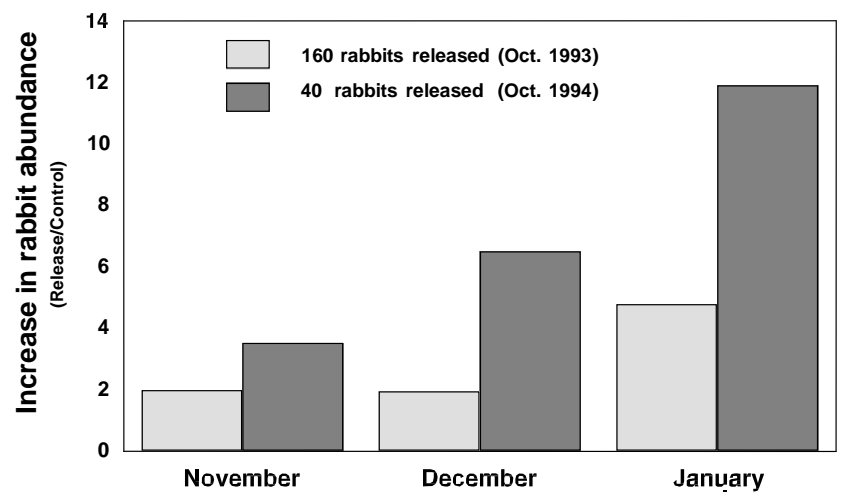

Fig. 5. Increase in rabbit abundance in the release vs. control areas in experiments involving the release of 40 and 160 rabbits in October 1994.

groups, although differences were not significant $(0.77$ vs. $0.43 ; \mathrm{z}^{1 / 4} 1$ :60, $\mathrm{P} 1 / 40: 12$ ). Predation by carnivores (mainly by foxes) was not significantly higher in the large group release than in the small one $(0.38$ vs. 0.11 ; $\mathrm{Z}^{1 / 4} 1: 56, \mathrm{P}^{1 / 4}$ 0:12).

\subsubsection{Spatial behaviour}

Rabbits in the large release group required more time to find a suitable place to settle in than rabbits in the small group (14.0 vs. 6.9 days; K-W 1/4 7.541, $\mathrm{P} 1 / 4$ 0:006). However, the rabbits in the large group exhibited a lower ID (64 vs. 137 m; K-W 1/4 5.486, P 1/4 0:002).

Rabbits in both groups exhibited similar maximum distances travelled $\left(\mathrm{K}-\mathrm{W}^{1 / 4} 1.15, \mathrm{P} 1 / 4\right.$ 0:283), similar dispersal indices (397 vs. $455 \mathrm{~m} ; \mathrm{F}_{1 ; 131} 1 / 4$ 0:97, $\mathrm{P}$ 1/4 0:325) and similar distances from their respective release points (dispersal from the release point: $\mathrm{K}-\mathrm{W} 1 / 40.810$, P $1 / 4$ 0:368).

\subsubsection{Rabbit abundance}

The increase in rabbit abundance measured by mean pellet numbers in the release area divided by mean pellet numbers in the control area was smaller when a large number of rabbits was introduced (Fig. 5). These differences increased over time. At the end of the third month after release, the increase in numbers in the small group was 12 times higher than in the control area, while for the large group, there was a more than fourfold increase in relation to the respective control population.

\section{Discussion}

4.1. First experiment. Evaluation of success according to restocking season

Our results show the success rates of four restocking experiments as measured by the comparison of survival rates in resident and introduced rabbits. In winter, there was considerable mortality among non-vaccinated resident rabbits due to RHD (Villafuerte et al., 1993): since RHD killed rabbits with maximum reproductive values (due to age and reproductive status) (Villafuerte, 1994), we might also conclude that disease is at least one of the factors which keeps resident rabbit numbers low.

Most of the deaths of the introduced rabbits in all four seasonal restockings occurred during the first few days after release. Probably, these recently introduced rabbits were more vulnerable due to their unfamiliarity with the habitat and their initial confusion and disorientation. The lack of shelter or possible stress during handling and transporting are other factors which increase predation risk (Bright and Morris, 1994; Letty et al., 2000). The higher ID during the first few days after release seems to reflect the aforementioned behaviour and fits the hypothesis that rabbit mobility influences predation risk (Norrdahl and Korpimfki, 1998). Introduced rabbits settled after a relatively short period (about one or two weeks). Settling time was relatively long in summer, i.e. the post-breeding period, which corresponds to low food availability (Villafuerte et al., 1997) and high resident population numbers, although other factors may be involved. On the other hand, the time needed to find a place to settle was shortest in winter, i.e. the pre-breeding period, when food is abundant and population numbers are at their lowest (Villafuerte et al., 1997). Once settled, introduced rabbits behaved like residents as regards their use of space, although they settled in a more widely dispersed distribution than resident radiotagged rabbits.

Progressive increases in rabbit abundance in the release as opposed to control areas were detected from summer to winter, probably indicating the success of the first three restockings. However, instead of an increase in numbers, a relative decrease was observed in spring (fourth release), just when the increase in numbers should have been greater in the release area. Nevertheless, survival rates were high and introduced and resident rabbits stayed in the release areas. Because mortality among introduced rabbits was low and dispersal was no higher than in other seasons, the absence of the expected post-breeding abundance peak was probably due to reduced productivity. This could have been because no young were born or because the newborn rabbits died. The sudden appearance of a stock of introduced rabbits in the breeding season (when density is high and social stress due to breeding is high; Vastrade, 1986; Cowan, 1987) may have had an impact on the resident population. This might lead to a disruption of the social structure, increasing agonistic behaviour and direct competition for resources (territorial areas and access to females in the case of males, and nest sites in the case of females; Kunkele, 1992), which could in turn decrease breeding success (Cowan and Garson, 1984) or lead to infanticide (Kunkele, 1992) and only 
finally giving rise to stable population numbers (Cowan and Garson, 1984).

The negative impact on production of young may lead to a lower abundance of lynxes and imperial eagles and probably especially affects all avian predators reliant on juvenile rabbits as prey (Villafuerte, 1994). However, wildlife managers, gamekeepers and hunters assume that the best season to release rabbits is during the period just before or during the breeding season (early spring or summer, Calvete et al., 1997). Our results seem to indicate the contrary, since the sudden intrusion of new rabbits during the breeding season precludes the expected population increase. Our results indicate that rabbit restocking should be carried out before the breeding season gets underway.

\subsection{Second experiment. Evaluation of success according to habitat quality}

Predation by mammalian carnivores (mainly foxes) was the only detected mortality factor for introduced rabbits in the two scrubland types. This data confirms previous studies in nearby areas (Villafuerte, 1994; Moreno et al., 1996), which have shown that predation by mammalian carnivores is a much more important cause of mortality in adult rabbits than predation by raptors. Predation rates - mainly due to foxes - were higher in dry scrubland. A multiple predation phenomenon happened in dry habitats after release: over a short period of time many dead rabbits were found buried but not eaten, or decapitated, as previously mentioned by Calvete et al. (1997). The sudden and artificially high concentration of rabbits after release might attract more predators and/or increase their foraging efficiency (Robertson, 1988; Brown and Litvaitis, 1995). Multiple predation was less acute in wet habitats, probably because the instantaneous increase in rabbit abundance was relatively lower in this habitat type, since the abundance before release was higher here than in dry habitats.

Rabbit movements in dry habitats were greater than in wet habitats, which may reflect the underlying causes of poor survival rates. If rabbit movements tend to reflect foraging, then when food is scarcer greater mobility will be necessary in order to find food. Thus, rabbits in dry habitats will be more exposed to predators (McNamara and Houston, 1987; Litvaitis, 1993), which may as a result take advantage of greater rabbit mobility (Norrdahl and Korpimaki, 1998). In fact rabbits exhibiting more wide-ranging behaviour did show a higher mortality rate, that is to say, rabbits in the pre-settlement period (in both habitat types) and rabbits in dry habitat (throughout the study period).

Seasonal variation in rabbit abundance, both in dry and wet scrubland types, reflected the typical patterns previously observed in the area (Beltrán, 1991; Villafu- erte et al., 1997). Rabbits introduced in autumn did not seem to reduce spring reproduction, as increases in numbers were detected in that season in both release areas. However, only in wet scrubland was restocking effective in increasing numbers, the post-breeding peak here being higher where rabbits were introduced. Rabbit abundance in the dry habitat release areas was lower than in the respective control area. Perhaps, because of the aforementioned predator attraction hypothesis, the resident rabbit population in the dry release areas suffered from higher predation rates than in the control areas. In any case, it seems clear that the limited carrying capacity (mainly food availability) of dry habitats means that they can only support small numbers of rabbits.

Our results suggest that habitat quality is a key factor in restocking success (Wolf et al., 1996). Rabbit restocking may be considered successful on wet scrubland, the best area for rabbits in Dorrana, but ineffective or even detrimental on dry scrubland, because here the habitat carrying capacity for rabbits is too low.

Moreno and Villafuerte (1995) have shown in the same type of study areas that traditional management (to increase the rabbit carrying capacity) in poor dry habitat was effective with regard to increasing lynx distribution. Consequently, restocking might be successful if habitat management was previously carried out to raise the carrying capacity.

\subsection{Third experiment. Large vs. small introduced rabbit numbers}

The success of the small restocking was greater than that of the large restocking. The release of 40 animals in October resulted in a 12-fold increase within three months, while the release of 160 rabbits only led to a fourfold increase. This agrees with the time needed to find a suitable place to settle (higher when a larger number of rabbits are introduced) and with the higher survival rate when a small number of rabbits were simultaneously released. This possibly occurred because the release of a larger number of animals resulted in an increase in predation immediately after the release date, as mentioned above. The causes of this relative failure when a big number of rabbits were introduced may resemble what happened in the dry areas, where the habitat does not provide enough carrying capacity to receive such a high number of rabbits. Moreover, the high concentration of rabbits after release could have increased the attractiveness of the area to predators (Robertson, 1988; Brown and Litvaitis, 1995) and led to a phenomenon of multiple predation when 160 rabbits were introduced. Hence, there may be an optimum number of rabbits that should be introduced to maximise population increases whilst minimising predation. This optimum number is probably related to the 
abundance of resident rabbits and the habitat carrying capacity. Because many conservationists and hunters directly equate releasing more rabbits with greater restocking efficiency, it is urgent to investigate the number of rabbits needed to ensure the success of a restocking programme.

\section{Conclusions}

In line with the IUCN position on the translocations of living organisms (www.uicn.org), whenever possible it is always better to manage habitat than to release animals. Although habitat management has been shown to be an efficient tool for enhancing rabbit populations for predator conservation in the Iberian peninsula, unfortunately there are still areas where endangered predators need urgent action plans and in such cases rabbit restocking may be a reliable management tool.

Although our study is essentially descriptive and being fully aware of the lack of replication in this experimental approach, we have shown that in terms of rabbit abundance the release of rabbits gives rise to either a positive or negative outcome and so we believe we are in a position to make some recommendations regarding rabbit restocking. (1) Restocking should be avoided during the breeding season for species showing strong social/family structures. (2) Sufficient resources must be available for introduced individuals. (3) Adequate number of animals should be introduced in relation to the carrying capacity and the abundance of the resident population.

\section{Acknowledgements}

We would like to thank G. Jordán, A. Jiménez and C. Quintero for their help during data collection, and Drs. R. Trout, F. Hiraldo, M. Delibes and L. Twigg, as well as two anonymous referees, for their useful recommendations and for revising the manuscript. The study was funded through the "Convenio de Cooperación ICONA-CSIC", BOS2001-2391-C02-01(CICYT), REN2001-0448/GLO and PBI-02-004 (Junta Comunidades de Castilla la Mancha).

\section{References}

Angulo, E., Cooke, B., 2002. First synthesize new viruses then regulate their release? The case of the wild rabbit. Molecular Ecology 11, 2703-2709.

Beltran, J.F., 1991. Temporal abundance patterns of the wild rabbit in Donana, SW Spain. Mammalia 55 (4), 591-599.

Branco, M.S., 1996. Contribuiçao para o estudo da genética bioquímica e populacional do coelho, Oryctolagus cuniculus. PhD thesis. University do Porto, Portugal.
Bright, P.W., Morris, P.A., 1994. Animal translocation for conservation: performance of dormice in relation to release methods, origin and season. Journal of Applied Ecology 31, 699-708.

Brown, A.L., Litvaitis, J.A., 1995. Habitat features associated with predation of New England cottontails: What scale is appropriate? Canadian Journal of Zoology 73, 1005-1011.

Calvete, C., Villafuerte, R., Lucientes, J., Osacar, J.J., 1997. Effectiveness of traditional wild rabbit restocking in Spain. Journal of Zoology 241, 1-7.

Castroviejo, J., 1993. Mapa del Parque Nacional de Dorrana. Consejo Superior de Investigaciones Científicas - Agencia de Medio Ambiente de la Junta de Andalucía (Eds.), pp. 133.

Chivers, D.J., 1991. Guidelines for re-introductions: procedures and problems. In: Gipps, J.H.W. (Ed.), Beyond Captive Breeding: Reintroducing Endangered Mammals to the Wild. Clarendon Press, Oxford, pp. 89-99.

Conover, W.J., 1980. Practical Nonparametric Statistics, 2nd ed. J. Wiley and Sons, New York.

Cowan, D.P., 1987. Aspects of the social organisation of the European wild rabbit (Oryctolagus cuniculus). Ethology 75, 197-210.

Cowan, D.P., Garson, P.J., 1984. Variation in the social structure of rabbit populations: causes and demographic consequences. In: Sibly, R.M., Smith, R.H. (Eds.), Behavioural Ecology. Blackwell Scientific Publications, Oxford, pp. 537-555.

Delibes, M., Hiraldo, F., 1981. The rabbit as prey in the Iberian Mediterranean ecosystems. In: Myers, K., MacInnes, C.D. (Eds.), Proceedings of the World Lagomorph Conference, University of Gtelph and Wildlife Research. Ministry of Natural Resources, Ontario, pp. 614-622.

Delibes, M., Rodríguez, A., Ferreras, P., 2000. Action Plan for the Conservation of the Iberian Lynx (Lynx pardinus) in Europe, no. 111. Council of Europe Publishing, Nature and Environment, Strasbourg, France.

Fenner, F., Fantini, B., 1999. Biological Control of Vertebrates Pests: the History of Myxomatosis - An Experiment in Evolution. CABI Publishing, Oxford, UK.

Ferrand, N., Branco, M., Villafuerte, R., Queirós, F., Moreno, S., 1993. Utilización de marcadores genéticos en la evaluación del resultado de las repoblaciones de conejo silvestre (Oryctolagus cuniculus) introducidos en el Parque Nacional de Dorana. I Jornadas Esparrolas de Conservación y Estudio de Mamíferos. Mollina, Málaga.

Ferrer, M., 2001. The Spanish Imperial Eagle. Lynx Edicions, Barcelona, Spain.

Galindo-Leal, C., Weber, M., 1994. Translocation of deer subspecies: reproductive implications. Wildlife Society Bulletin 22, 117120.

Heisey, D.M., Fuller, T.K., 1985. Evaluation of survival and causespecific mortality rates using telemetry data. Journal of Wildlife Management 49, 668-674.

ICONA-CSIC, 1988. Plan de manejo del lince, Lynx pardina, en el Parque Nacional de Dorrana (Huelva, Espara). Instituto Nacional para la Conservación de la Naturaleza y Consejo Superior de Investigaciones Científicas.

Karesh, W.B., 1993. Cost evaluation of infectious disease monitoring and screening programs for wildlife translocations and reintroduction. Journal Zoology and Wildlife Medicine 24, 291-295.

Kunkele, J., 1992. Infanticide in wild rabbits (Oryctolagus cuniculus). Journal of Mammalogy 73, 317-320.

Letty, J., Marchandeau, S., Clobert, J., Aubineau, J., 2000. Improving translocations success: an experimental study of anti-stress treatment and release method for wild rabbits. Animal Conservation 3, 211-219.

LIFE-CE, 1992. Programa de Acciones para la Conservación del Águila Imperial Ibérica. Proyecto LIFE (European Community).

Litvaitis, J.A., 1993. Response of early successional vertebrates to historic changes in land use. Conservation Biology 7, 866-873. 
Lombardi, L., Fernández, N., Villafuerte, R., Moreno, S., 2003. Habitat related change in rabbit abundance, distribution and activity. Journal of Mammalogy 84, 26-36.

McNamara, J.A., Houston, A.I., 1987. Starvation and predation as factors limiting population size. Ecology 68, 1515-1519.

Meltzer, D.G.A., 1993. Historical survey of disease problems in wildlife populations: Southern Africa mammals. Journal of Zoology and Wildlife Medicine 24, 237-244.

Moreno, S., Villafuerte, R., 1995. Traditional management of scrubland for the conservation of rabbits Oryctolagus cuniculus and their predators in Dorana National Park, Spain. Biological Conservation 73, 81-85.

Moreno, S., Villafuerte, R., Delibes, M., 1996. Cover is safe during the day but dangerous at night: the use of vegetation by European wild rabbits. Canadian Journal of Zoology 74, 1656-1660.

Nielsen, L., 1988. Definitions, considerations, and guidelines for translocation of wild animals. In: Nielsen, L., Brown, R.D. (Eds.), Translocation of Wild Animals. Wisconsin Humane Society, Milwaukee, pp. 12-51.

Norrdahl, K., Korpim€ki, E., 1998. Does mobility or sex of voles affect risk of predation by mammalian predators? Ecology 79, 226-232.

Nowell, K., Jackson, P., 1996. Wild Cats: Status Survey and Conservation Action Plan. International Union for Conservation of Nature Publications, Gland, Switzerland.

Palomares, F., 2001. Comparison of 3 methods to estimate rabbit abundance in a Mediterranean environment. Wildlife Society Bulletin 29, 578-585.

Palomares, F., Delibes, M., Revilla, E., Calzada, J., Fedriani, J.M., 2001. Spatial ecology of Iberian lynx and abundance of European rabbits in southwestern Spain. Wildlife Monografe 148, 1-36.

Robertson, P.A., 1988. Survival of released pheasants, Phasianus colchicus, in Ireland. Journal of Zoology 214, 683-695.
Robinette, K.W., Andelt, W.F., Burnham, K.P., 1995. Effect of group size on survival of relocated prairie dogs. Journal of Wildlife Management 59, 867-874.

Rogers, P.M., Arthur, C.P., Soriguer, R.C., 1994. The rabbit in continental Europe. In: Thompson, C.M. (Ed.), The European Rabbit. The History and Biology of a Successful Colonizer. Oxford University Press, Oxford, pp. 22-63.

Valverde, J.A., 1958. An ecological sketch of the Coto Dorrana. British Birds 51, 1-23.

Vastrade, F.M., 1986. The social behaviour of free-ranging domestic rabbits (Oryctolagus cuniculus L). Applied of Animal Behaviour Science 16, 165-177.

Viggers, K.L., Lindenmayer, D.B., Spratt, D.M., 1993. The importance of disease in reintroduction programmes. Wildlife Research $20,687-698$

Villafuerte, R., 1994. Riesgo de predación y estrategias defensivas del conejo, Oryctolagus cuniculus, en el Parque Nacional de Dorrana. $\mathrm{Ph}$.D. thesis, Universidad de Córdoba, Esparra.

Villafuerte, R., Calvete, C., Gortázar, C., Moreno, S., 1993. First epizootic of rabbit haemorrhagic disease (RHD) in free living populations of Oryctolagus cuniculus at Dorana National Park, SW Spain. Journal of Wildlife Disease 30, 176-179.

Villafuerte, R., Lazo, A., Moreno, S., 1997. Influence of food abundance and quality on rabbit fluctuations: conservation and management implications in Dorana National Park (SW Spain). Revue d'Ecologie (Terre Vie) 52, 345-356.

Woodford, M.H., 1993. International disease implications for wildlife translocations. Journal of Zoology and Wildlife Medicine 24, 265270.

Wolf, C.M., Griffith, B., Reed, C., Temple, S.A., 1996. Avian and mammalian translocations: Update and reanalysis of 1987 survey data. Conservation Biology 10, 1142-1154. 